\title{
Closing spaces with the lingual technique in cases of agenesis of the upper lateral incisor
}

\section{Frédéric BONNIN}

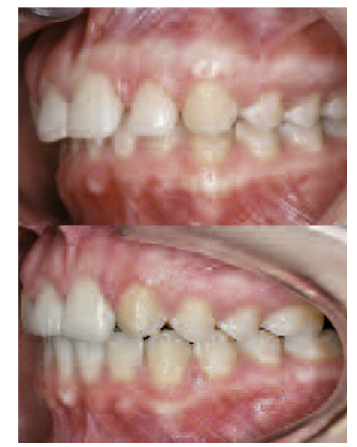

\begin{abstract}
SUMMARY
How to close gaps with the lingual technique in cases of agenesis of the upper lateral incisor is a therapeutic decision orthodontists often have to make. We have decided to discuss the mechanical and strategic aspects of this issue that arise when we implement the lingual technique to treat this disorder, which is a major source of concern for our patients since its esthetic repercussions for the smile are so great.
\end{abstract}

\section{KEY WORDS}

Dental ageneses,

Lingual technique.

\section{1 - INTRODUCTION}

"With respect to the destiny of the individual, a small missing incisor may not seem to be all that important. However, if the presence of a grain of sand can hinder the workings of a powerful machine, in the same vein the absence of a single tooth can change the appearance, and disorganize the functioning of this marvelous and complex ensemble which comprises the face."

This is how Julien Philippe introduced the question of agenesis of a maxillary lateral incisor when this topic was discussed by the French Society of Orthodontics and DentoFacial Orthopedics in 1987. The uncertainty and compromising nature of our therapeutic choices proving that this subject continues to preoccupy us.

The implant solution appeals to many of us because of our academic training: respecting the rules of occlusion and maintaining the privileged relationship of the class I molar and canine, respecting mandibular kinesthesia, preserving the periodontal environment of the canines and premolars, and maintaining the dental 
harmony that the presence of the six teeth making up the smile assures.

The considerable progress made in implantology also makes it possible to ensure the stability and retention of a fixed prosthesis. However, we have to admit our disappointment regarding the durability of these prostheses: the appearance of the metal abutment because of gingival recession that takes place over time ${ }^{8}$ or a discoloration of the gingiva (in 50\% of the cases immediately after the implant $^{3}$ is inserted according to the authors).

At the same time, the results are disappointing in the long term because the implant does not follow the passive and continuous eruption of the denture and this inevitably leads to development of open bites $^{8,9,10,15}$.

Marco Rosa $^{13}$ perfectly sums up the advantages and disadvantages of the implant solution:

- Advantages:

- optimal posterior occlusion;

- short-term satisfactory esthetic result;

- comparatively simpler and shorter orthodontic treatment;

- no need for prosthesis or reconstruction of neighboring teeth;

- reliable long-term osteointegration;

- Disadvantages:

- progressive appearance of open bites;

- torque that is not equivalent with that of the natural incisors;

- discoloration of the gingiva;

- appearance of a metal collar over time;

- inter-dental recession particularly of the distal papillae;
- difficulty in making the ceramic crown look natural;

- a clinical track record that lasts no more than 10 to 15 years.

Accordingly, the SFODF in $1987^{1}$

summarized the advantages and disadvantages of closing the gaps, which is the second option:

- Advantages:

- avoids resorting to a prosthesis;

- reestablishes the continuity of the natural teeth;

- easy integration into a treatment plan involving extractions in the lower arch;

- Disadvantages:

- require long and difficult treatment to obtain good interproximal contacts, good intercuspation, good occlusion, and satisfactory group function (set-up), and a post-orthodontic equilibration;

- does not reestablish the canine to class I;

- requires reshaping the canine;

- there is a risk of reducing the profile, of worsening the effects of a very marked horizontal growth or worsening a retrusive profile.

Rosa and Zachrisson exploit solutions developed by cosmetic dentistry $^{11,12}$ to help the canines masquerade as lateral incisors.

Since the lingual technique makes it possible to efficiently accomplish both objectives, we are going to explore the strategic and mechanical particularities inherent to closing gaps caused by congenitally missing upper lateral incisors.

We shall mainly rely on two clinical cases using the incognito ${ }^{\circledR}$ technique to illustrate our remarks. 

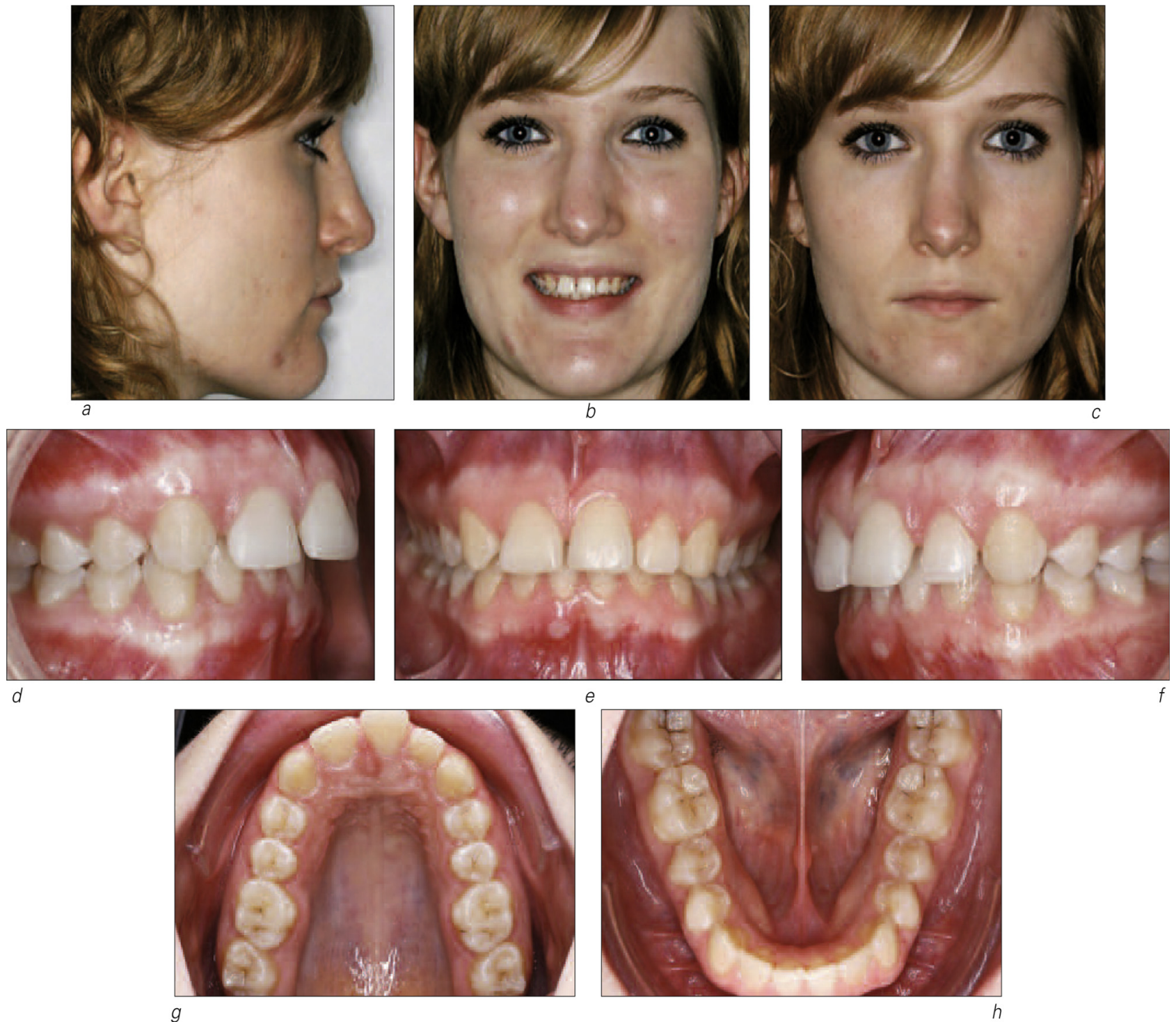

Figures 1a to $1 \mathrm{~h}$

Clinical case $n^{\circ} 1$.

Clinical case $\mathrm{n}^{0} 1$ (Fig. 1) is that of a young woman, 21 years old presenting a unilateral agenesis of 12 . Her typology is normodivergent. She presents no skeletal malformation but a clinical upper alveolar protrusion resulting in a class $I I$ molar and canine relationship. The lower arch is uncrowded but the asymmetry of the upper arch entails a deviation of the central incisor to the right. The patient consented to have the upper left lateral incisor extracted in order to correct this midline deviation and to reduce the upper alveolar protrusion. At the end of orthodontic treatment the molars will be left in therapeutic class II occlusion and the canines will be masqueraded as lateral incisors. 


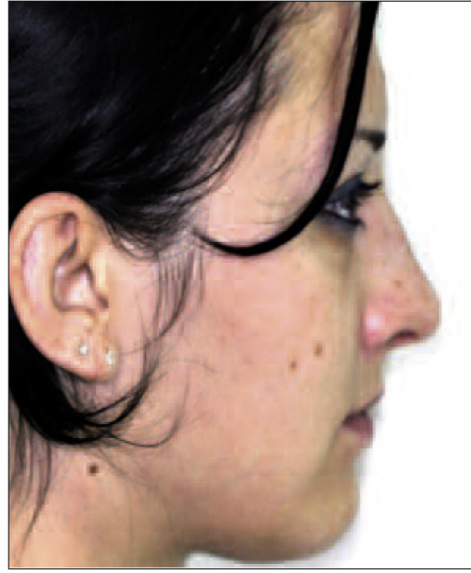

a

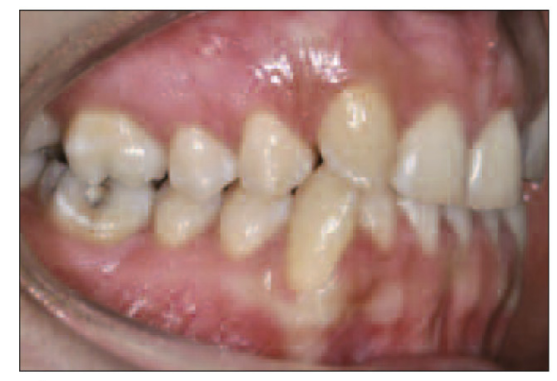

d

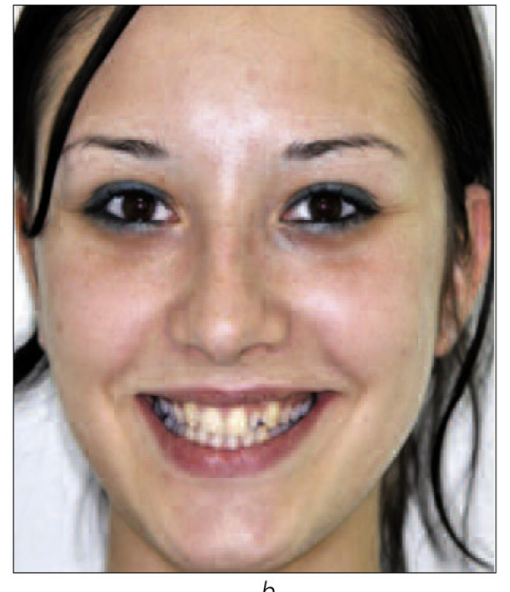

$b$

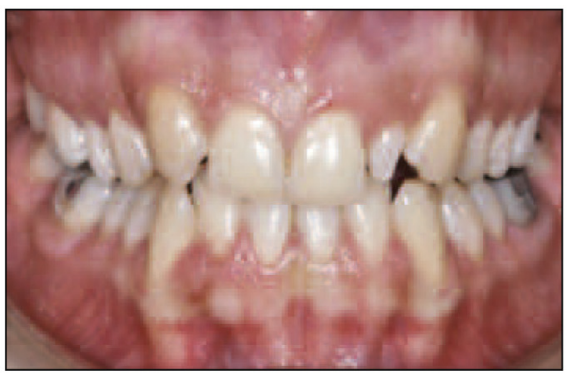

e
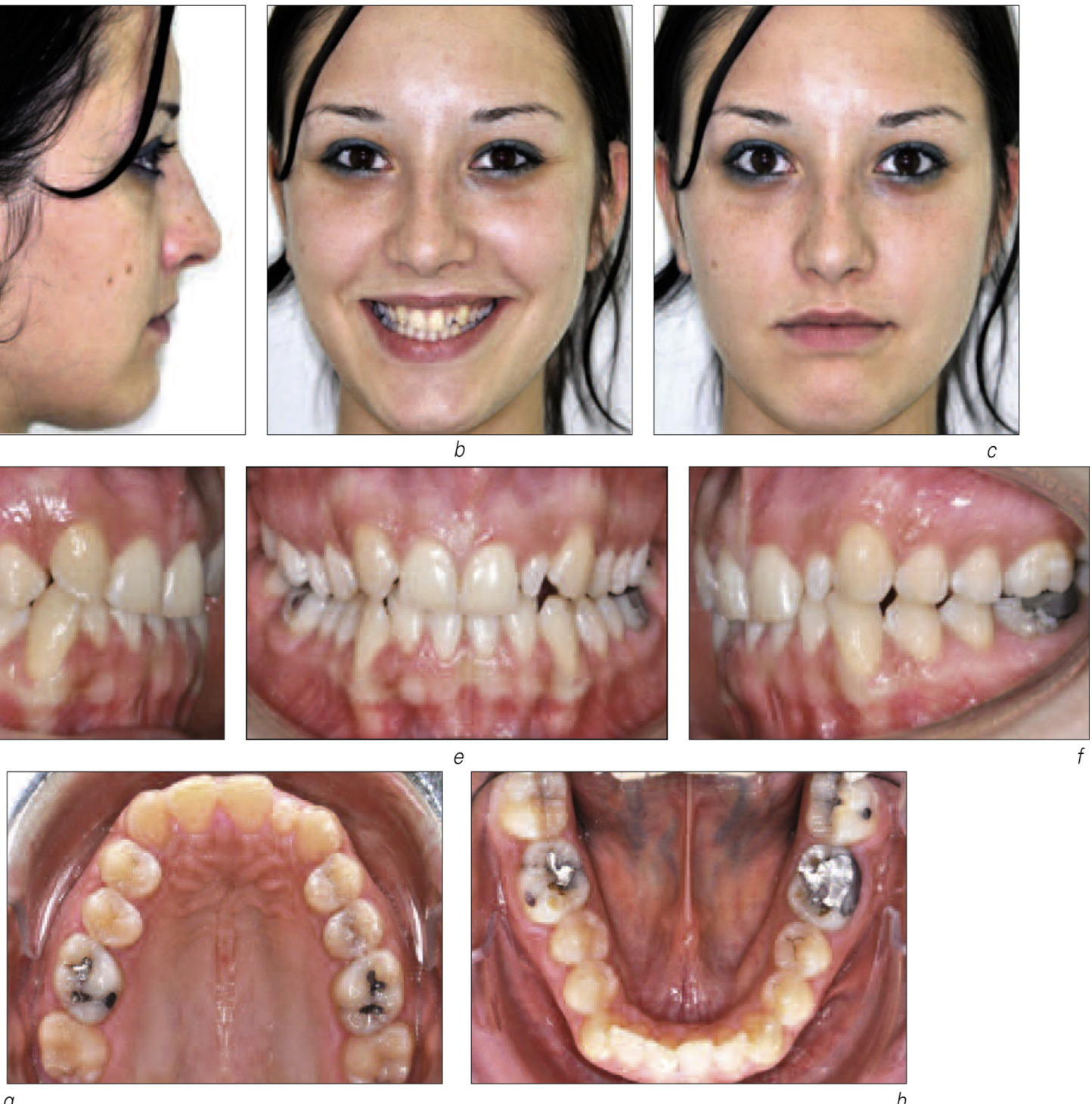

Figures 2a to $2 \mathrm{~h}$

Clinical case $n^{\circ} 2$.

Case $n^{\circ} 2$ is rather similar since the upper left lateral is missing and there is no skeletal problem (Fig. 2). However, the upper left lateral is stunted and there is moderate crowding in the lower arch. The upper central incisor is also unattractively tilted toward the side of the agenesis. Finally, there is no upper alveolar protrusion instead there is a certain degree of bimaxillary alveolar retrusion, which makes the profile of this patient slightly concave. We suggested the same treatment for her: extraction of the stunted upper left lateral incisor and closing of the gaps. 


\section{2 - STRATEGIC PARTICULARITIES}

\section{2 - 1 - Reshaping the canine}

\section{2-1-1 - Changing crown by build up}

It is recognized that masquerading the canine must be performed at the end of orthodontic treatment. Rosa ${ }^{13}$ recommends that the crown be reconstructed the same day as the orthodontic appliance is removed in order to create a shape that is both esthetic and functional while restoring the contact points with the adjacent teeth. This reconstruction must also make it possible to create a cast of the upper interdental papillae, which are crucial elements of the esthetics of the smile.

The practitioner must choose the composite to harmonize with the color of the central incisor, so that after whitening, the canine enamel will match the reconstruction composite, making it invisible.

It is then possible to attach the palatal arch wire from premolar to premolar.

Canal $^{2}$ recommends the placement of a maxillary wire that covers the palatal surface of the first premolar rather than the occlusal surface.

The breakdown or devitalization of one or more dental elements can make it necessary for veneers or ceramic crowns to be constructed. Therefore, it is recommended that the orthodontist wait until the end of the retention period before performing these orthodontic procedures. Further on, we will revisit the planning and coordination between cosmetic dentistry and orthodontic retention. The patient is often in a hurry to recover an impeccable smile at the end of active treatment, without necessarily having in mind that all the prosthetic work requires perfect retention of all the formerly misaligned teeth.

\section{2-1-2 - Crown reshaping, correction by grinding}

In this case, the coronoplasty of the canine must be done in accordance with the stripping chart chosen by the practitioner and recorded on the laboratory sheet. Stripping must be performed during the installation of the upper super flexible nitinol wire.

While crown reshaping mesio-distally usually causes no problems, the situation is different-bucco-palatally because the palatal surface of the canine is often necessary to obtain a satisfactory anterior guidance and generalized contacts with the free edges of the lower incisor group.

This creates a problem when using the lingual technique because bracket placement makes this procedure impossible during the finishing phase.

Therefore, it seems to us to be indispensable to ask the laboratory for a visualization of the set-up before fabricating the appliance (Fig. 3).

The practitioner can choose to ask the lab technician, to compensate by default its thickness and intrude the canine. The development of virtual set-up techniques should make it possible for the practitioner to more 


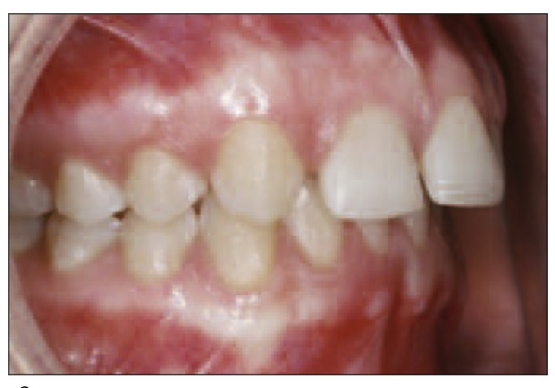

a

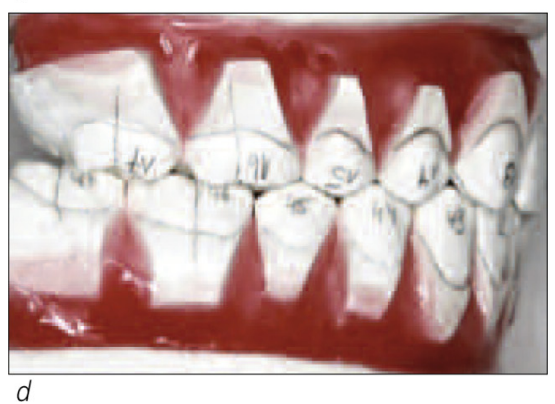

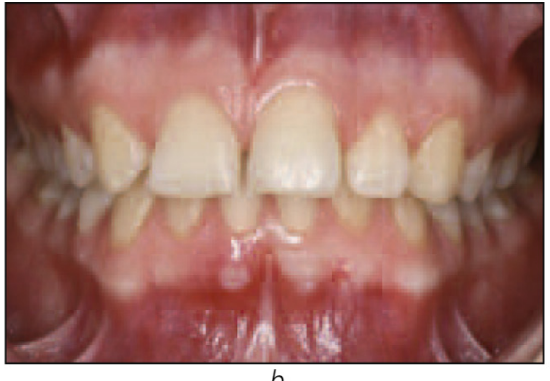

b

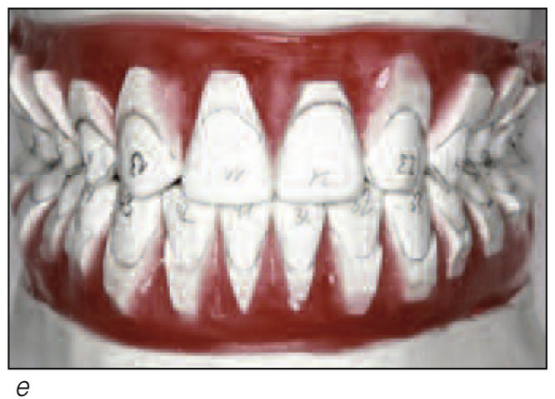

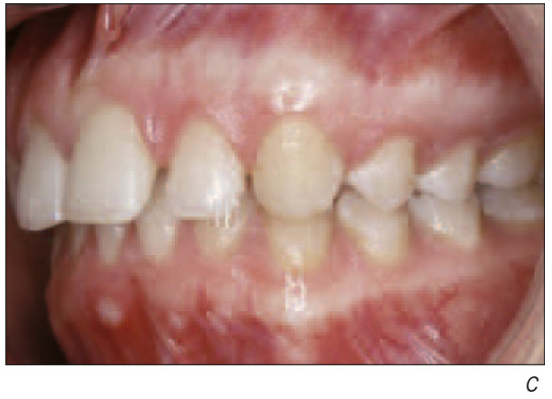

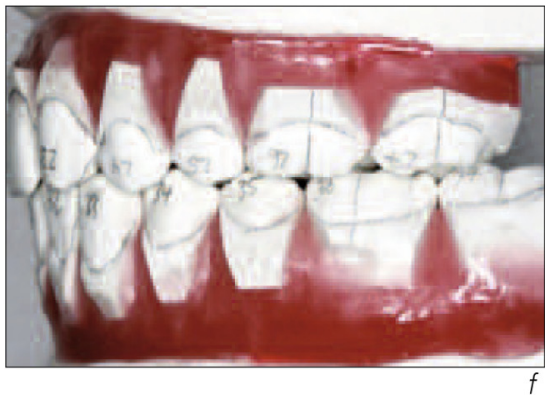

Figures $3 a$ to $3 f$

Clinical case $n^{0} 1$. Visualization of the anterior intrusion on the set-up before making the device.

easily control the tridimensional placement of the canine before the lab fabricates the device.

However, when the canine has a bucco-lingual thickness that is too disproportionate in relation to that of the central incisor and the compensatory intrusion would be excessive, we suggest that the practitioner reduce the palatal surface of the canine before taking silicone impressions since it will no longer be possible to do it afterwards.

\section{2 - 2 - Consolidation of the four anterior teeth}

This is an imperative of the first order. It will be difficult, even dangerous to perform this procedure with a rectangular arch because torque will complicate mesialization of the canines (Fig. 4).

Therefore, we highly recommend the use of a round arch during the first procedure (Fig. 5).

Fabricating the individualized archwire from a commercial archwire turned out to be necessary because the anterior part of the archwire provided by the lab is often too short. However, it is possible to compensate for this deficit by using one of three other solutions suggested by Galletti ${ }^{6}$ when the anterior part of the archwire is too short.

\section{2 - 3 - Making roots parallel}

This is by far the most difficult objective to attain. A panoramic radiograph will make it possible to 

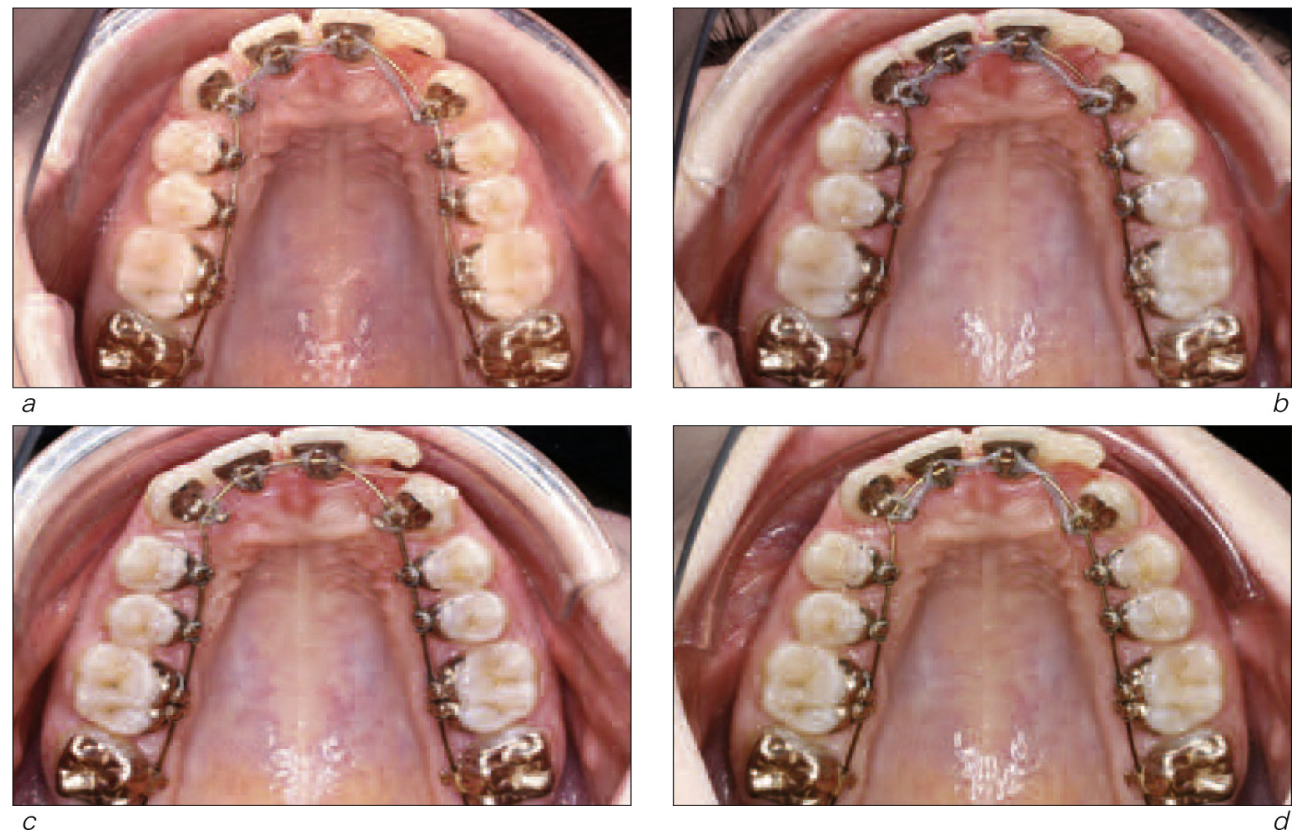

Figures $4 a$ to $4 d$

Clinical case $n^{\circ}$ 1. Failed attempt to mesialize the upper left canine on a rectangular super flexible 16 by 22 archwire over a 6 month period.
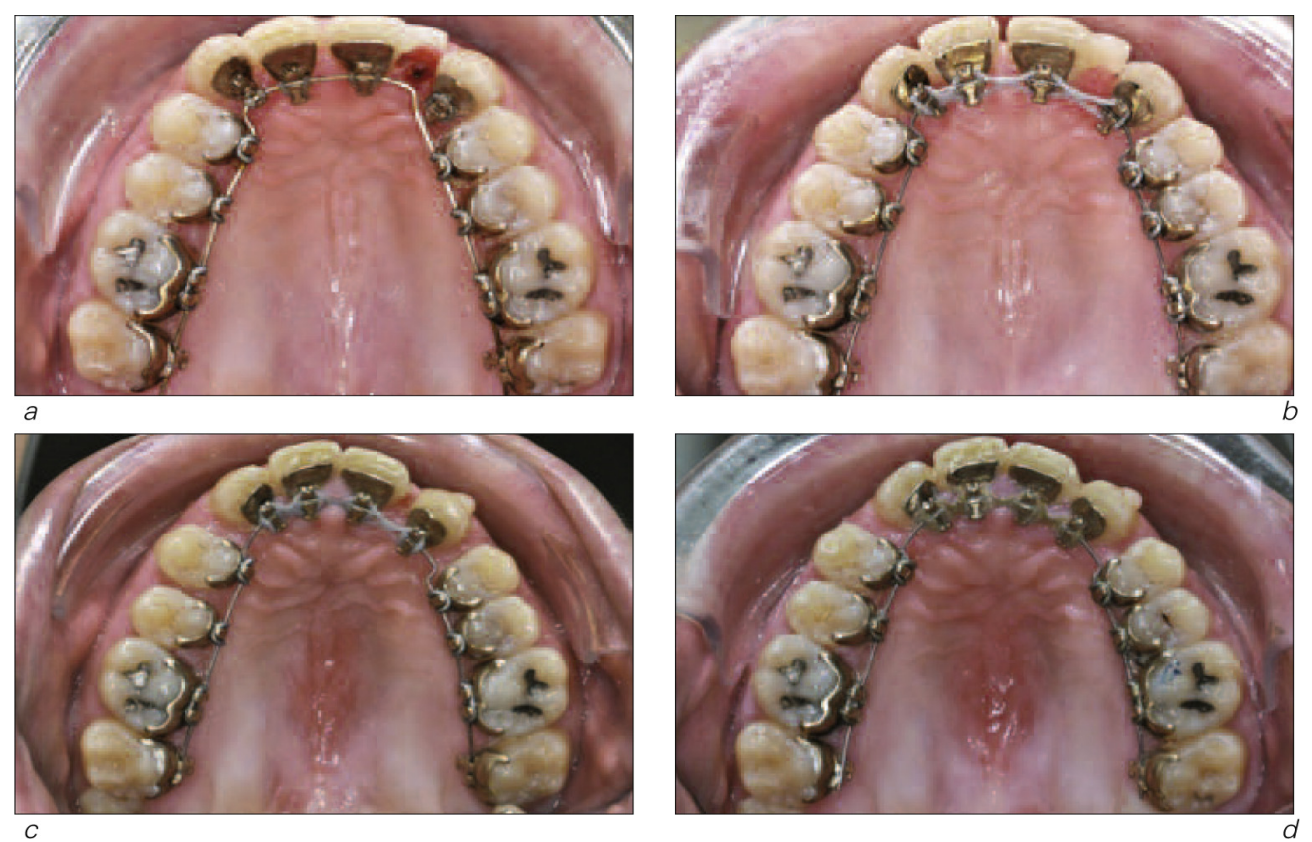

Figures 5 a to $5 d$

Clinical case $n^{\circ}$ 2. Easy mesialization with a round 0.16 super elastic archwire after leveling the upper left cuspid in 6 months. 

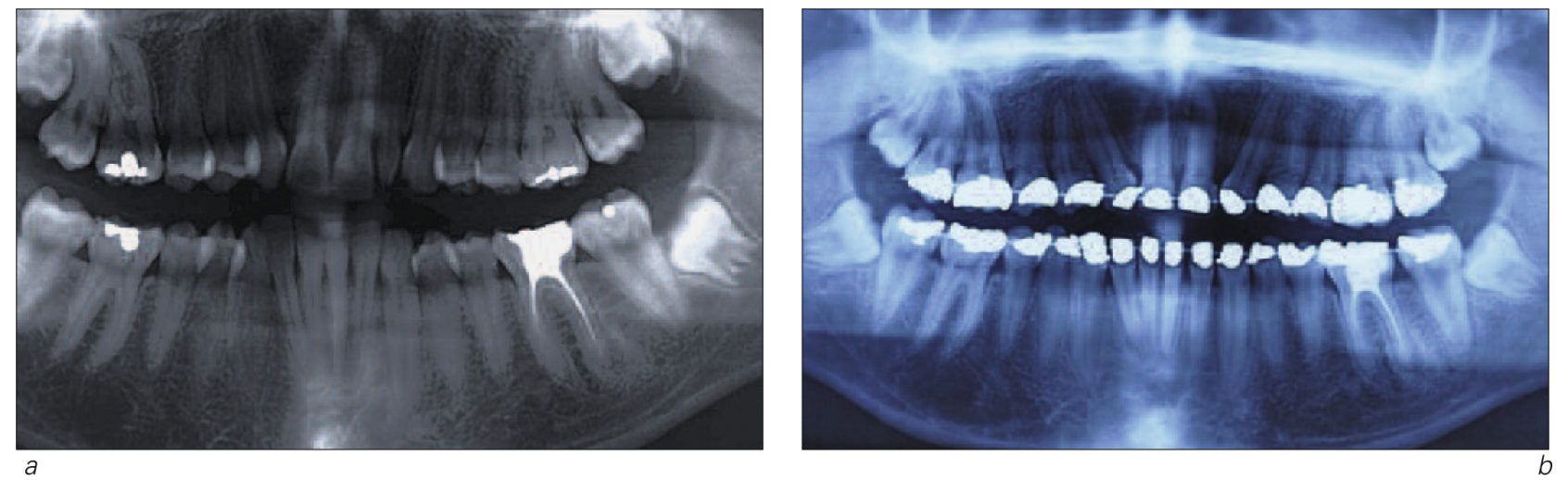

Figures $6 a$ and $6 b$

Check-up radiogram after mesialization of the canines.
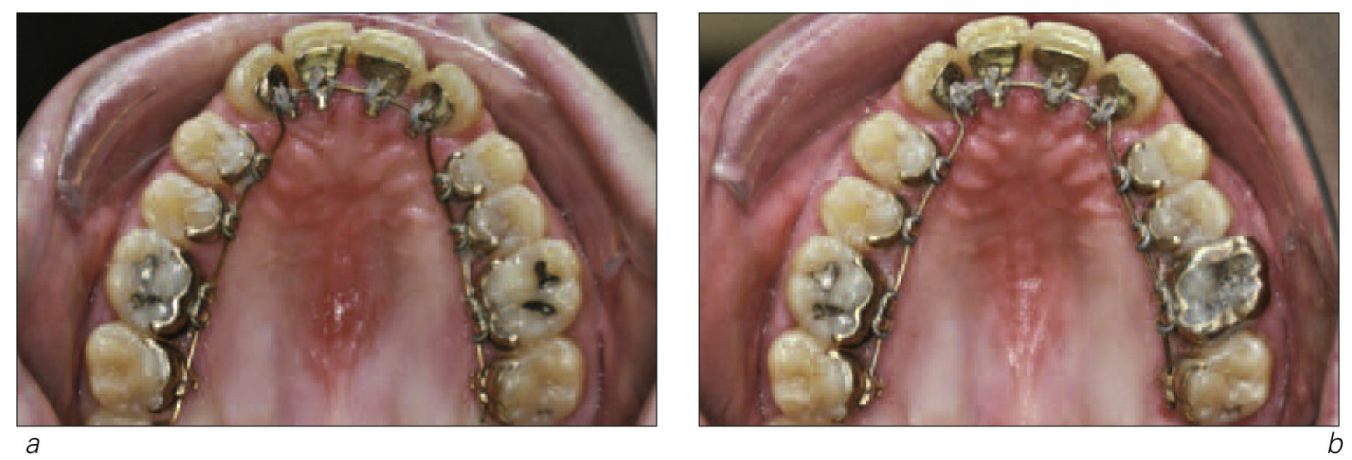

Figures $7 a$ and $7 b$

Clinical case $n^{\circ}$ 2. Figure 8 ligature had been removed before the picture on the right was taken in order to increase the performance of the power-ties.

measure how much root uprighting will be required (Fig. 6).

The placement of the 16 by 22 and 18 by 25 super elastic archwires must be done at this stage. Using power-ties will reinforce their pressure.

Using an 8-braid ligature can maintain contact between the four anterior teeth but it will diminish the performance of the power-ties (Fig. 7).

\section{2 - 4 - Closing the gaps}

Usually this will be accomplished with a steel archwire for smoother sliding with perfect control of torque. It is imperative to ask for an increase of anterior torque from canine to canine (in relation to standard values) as in all cases of extractions.

The recommended archwire using the Incognito ${ }^{\circledR}$ technique is the steel 16 by 24 (extra torque) with 


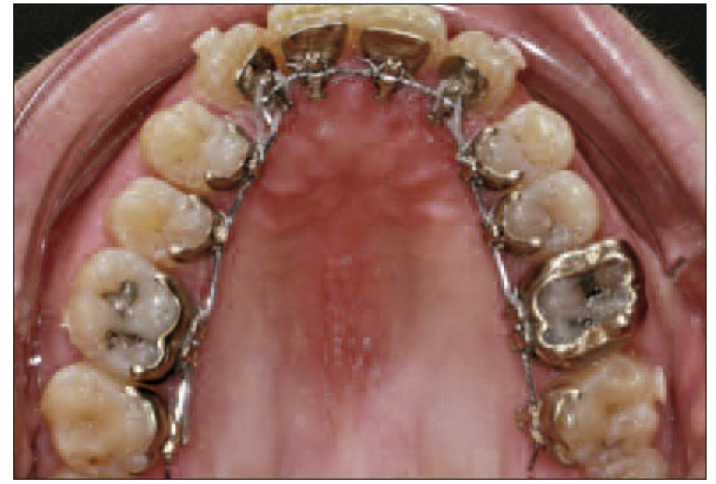

Figure 8

Clinical case $n^{\circ}$ 2. Placement of the extra-torque steel 16 by 24 archwire and closing the gaps.

- 8 braid ligature under the archwire on the anterior part;

- double metallic over-ties on the canines;

- metallic ligatures on all the other teeth;

- stretched bracket under the archwire between canine and second molar.

The practitioner must not forget to ask the lab for archwires with straight lateral sectors unilaterally on the side of the extraction in order to facilitate the mechanics of sliding.

The insertion of this archwire is made easier by the use of 18 by 25 super elastic during the preceding phase.

Should the retraction be done after grouping the four anterior teeth? We noticed that this grouping is sometimes difficult to achieve (Fig. 4). Additionally, this grouping required that we create back and forth movements that can harm the dentition if they are too great. Therefore, for clin- ical case $\mathrm{n}^{0} 1$ where the upper alveolar protrusion was pronounced, closing the gaps was performed at the end of leveling without mesializing cuspids beforehand (Fig. 9).

This choice of treatment calls for several remarks:

- movement cannot be continuous. The practitioner will have to interrupt it when the canine abuts a $1^{\text {st }}$ order bend, archwires created with the Incognito ${ }^{\circledR}$ technique are shaped like a mushroom. This will require starting the leveling over again using a super elastic arch (Fig. 9);

- the canine will even be lingualized at the end of the retraction which will require a painstaking and longer final procedure (Fig. 10).

Without categorically stating that the procedure should always be performed, the strategy that we chose to treat case $n^{\circ} 1$, turned out to be faster than the more by the book grouping of the four anterior teeth which determined the treatment chosen for case $n^{\circ} 2$.

\section{2 - 5 - Retention and coordination with an orthodontic-dentofacial prosthesis}

Retention from premolar to premolar is essential to maintaining the six anterior teeth in position and to avoid reopening the diastemas (Fig. 11).

However, it is still difficult to manage the rapid insertion of a splint 

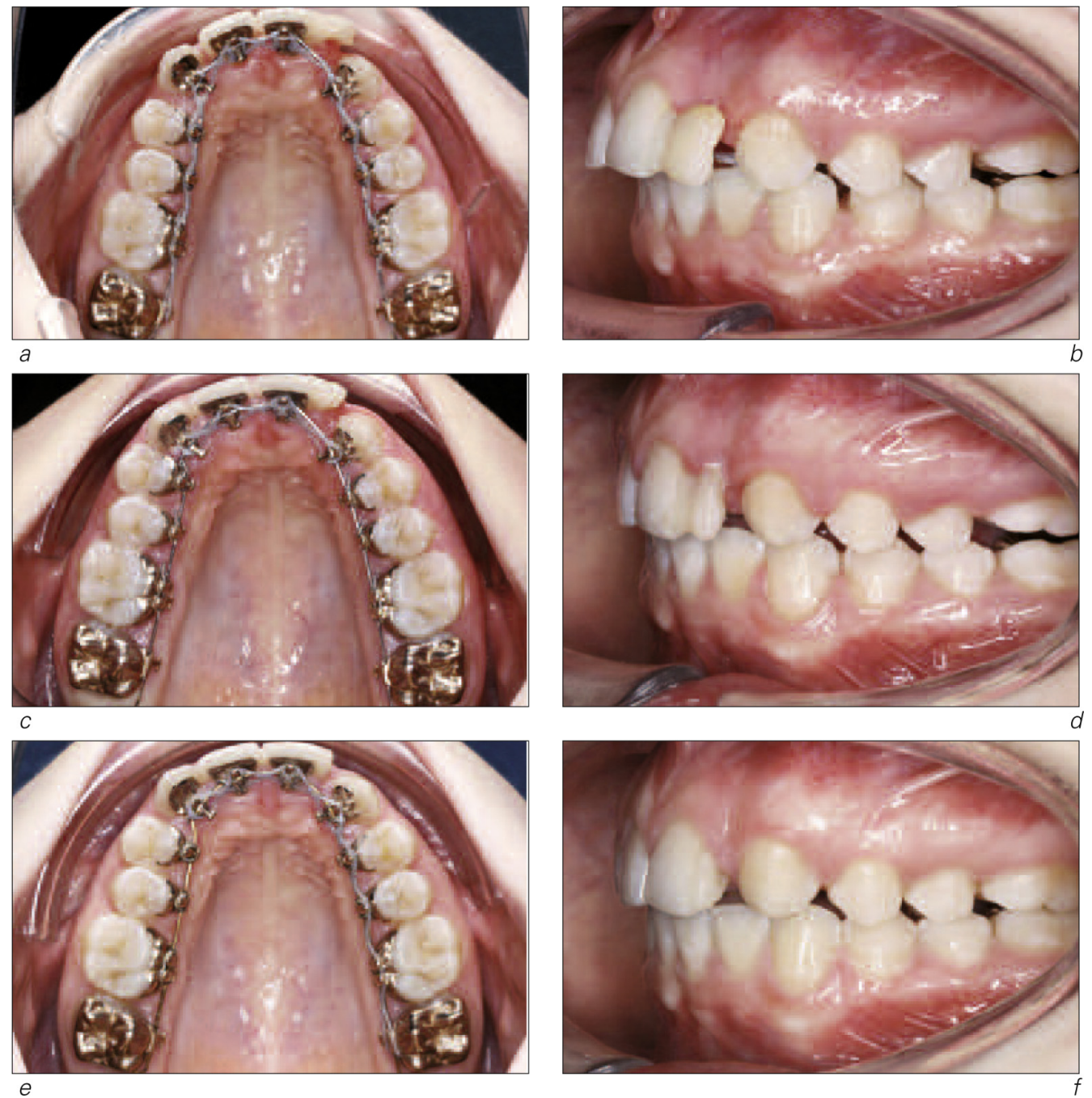

Figures 9a to $9 f$

Closing spaces without mesializing the canine beforehand by the intermediary reuse of the super elastic archwire during retraction.

without impeding the prosthetic action of disguising the canines (Fig. 12).

It is recommended that the practitioner coordinate these actions on the same day:

- inserting the device;

- doing prosthetic preparation on the canines;

- taking an impression of the bonded veneers;
- making a splint for temporary retention.

Depending on the delays imposed by the prosthetic lab, a few days later the following procedures take place:

- insertion of the bonded veneers;

- insertion of the retention wire;

- end of period for wearing the temporary splint. 

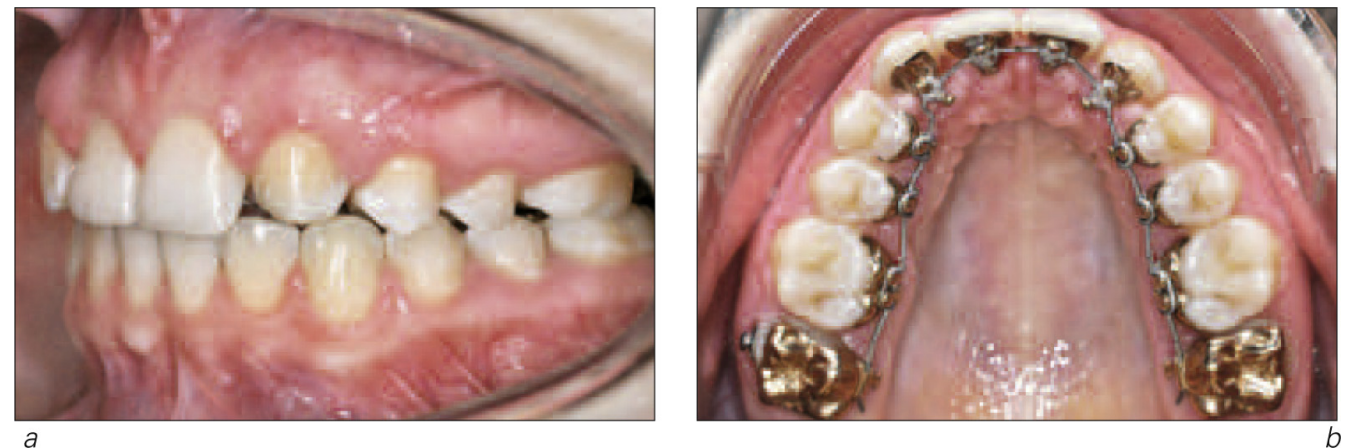

Figures 10a and $10 \mathrm{~b}$

Situation of the canine at the end of retraction during placement of the finishing archwire.

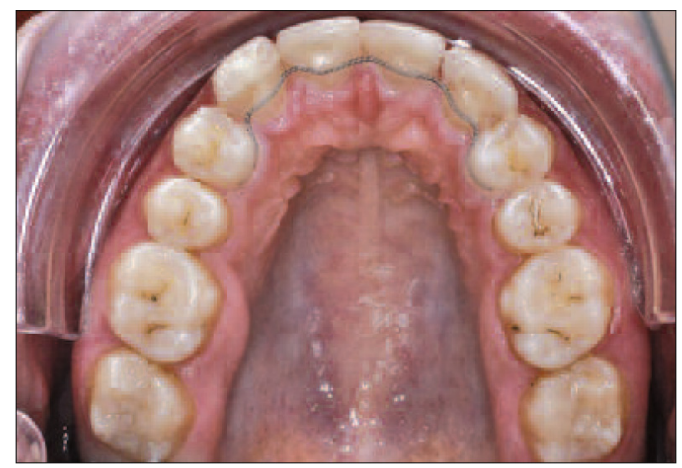

Figure 11

Clinical case $n^{\circ}$ 1. Retention wire conforms to the recommendation of Canal ${ }^{2}$.

\section{2 - 6 - Strategy for reopening the posterior space}

As we stated in the introduction, there are clinical situations that are not conducive to closing spaces.

In such cases, it is possible to plan the insertion of one or several implants more distally. This choice includes the advantage of not reducing the number of teeth in the arch while at the same time placing implants in a zone where gingival esthetics are much easier to manage.
Therefore, in cases of ageneses of upper lateral incisors, the practitioner can plan on leaving the canines mesialized in contact with the central incisors and placing " 3 rd molar" type posterior implants.

Clinical case $n^{0} 3$ (a case treated by Dr. Magali Mujajic) shows this option which consists of reopening two implant spaces between the upper premolars (Fig. 13). A Locatelli spring makes it possible to mesialize the first premolars more easily. 


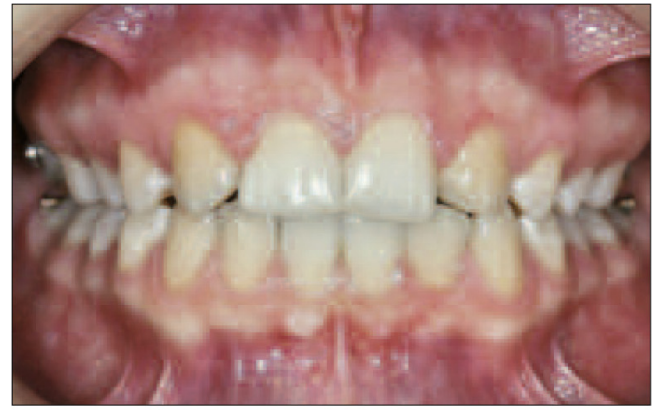

a

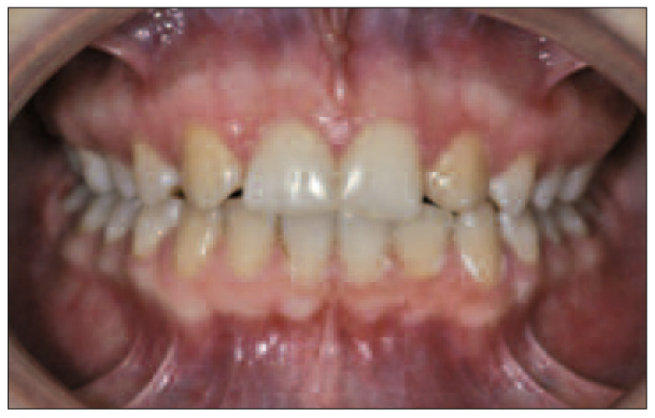

C

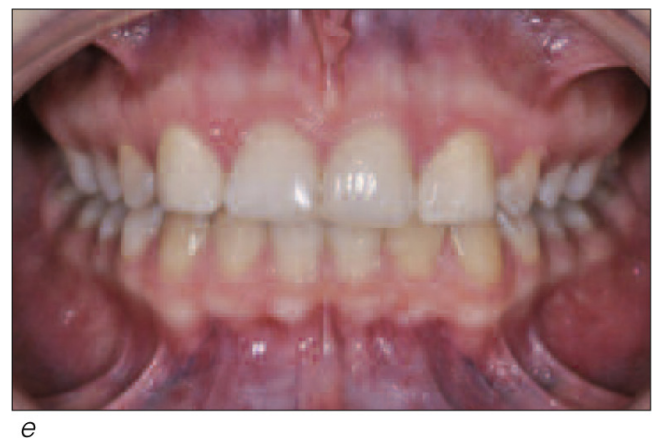

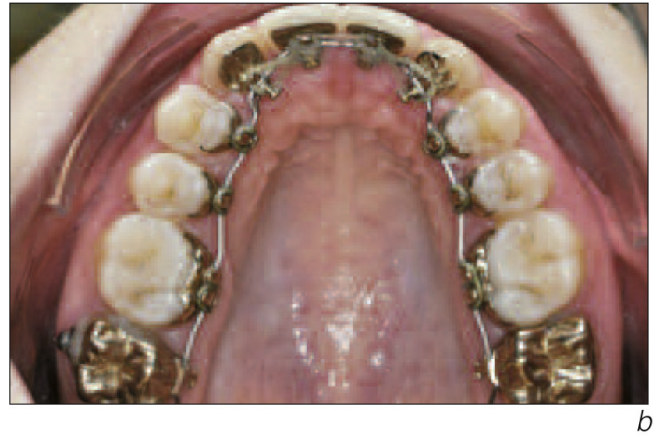
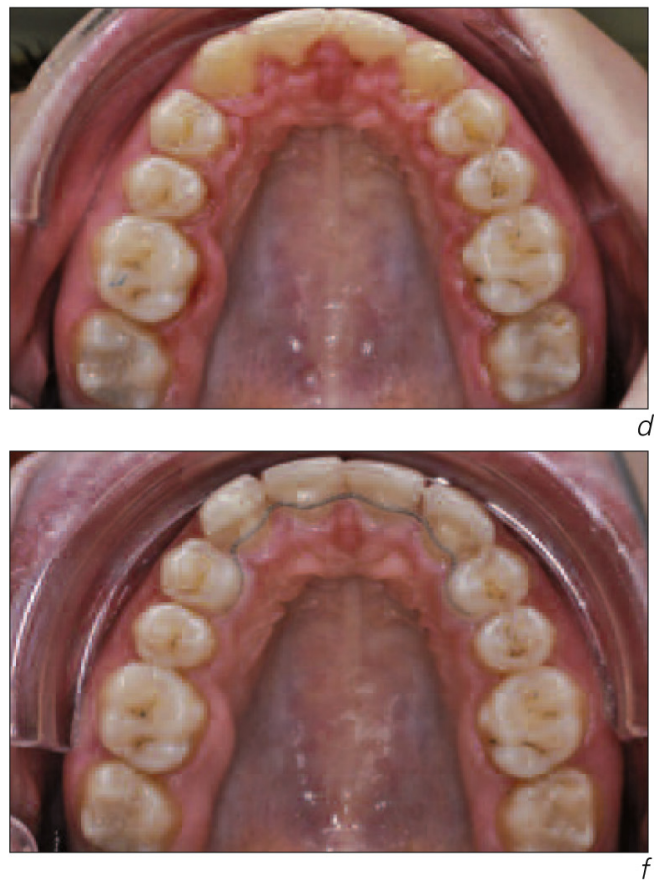

Figures $12 a$ to $12 f$

Clinical case $n^{\circ} 1$, a and b: before placement of orthodontic device; $c$ and d: after insertion of orthodontic device but before prosthesis; $e$ and f: after insertion of ceramic veneers and retention wire.

The development of multidisciplinary orthodontics for adults and active collaboration with our periodontal and implantologist colleagues combine to promote a very prudent approach in choice of treatment, which consists of planning for implants in the place of the upper lateral incisors. Since complete closing of spaces is not always indicated as we just saw, the strategy which consists of moving the site of the future implant distally must be included among possible and manageable solutions. 


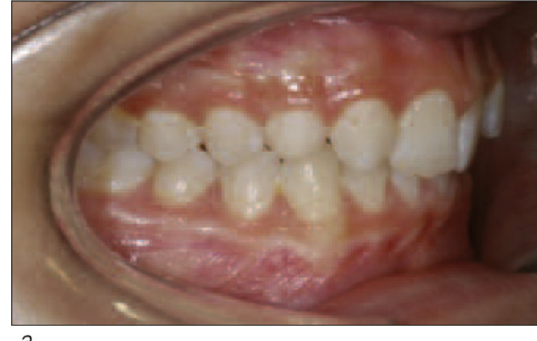

a

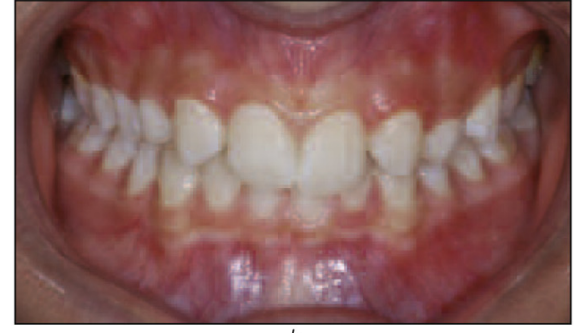

$b$
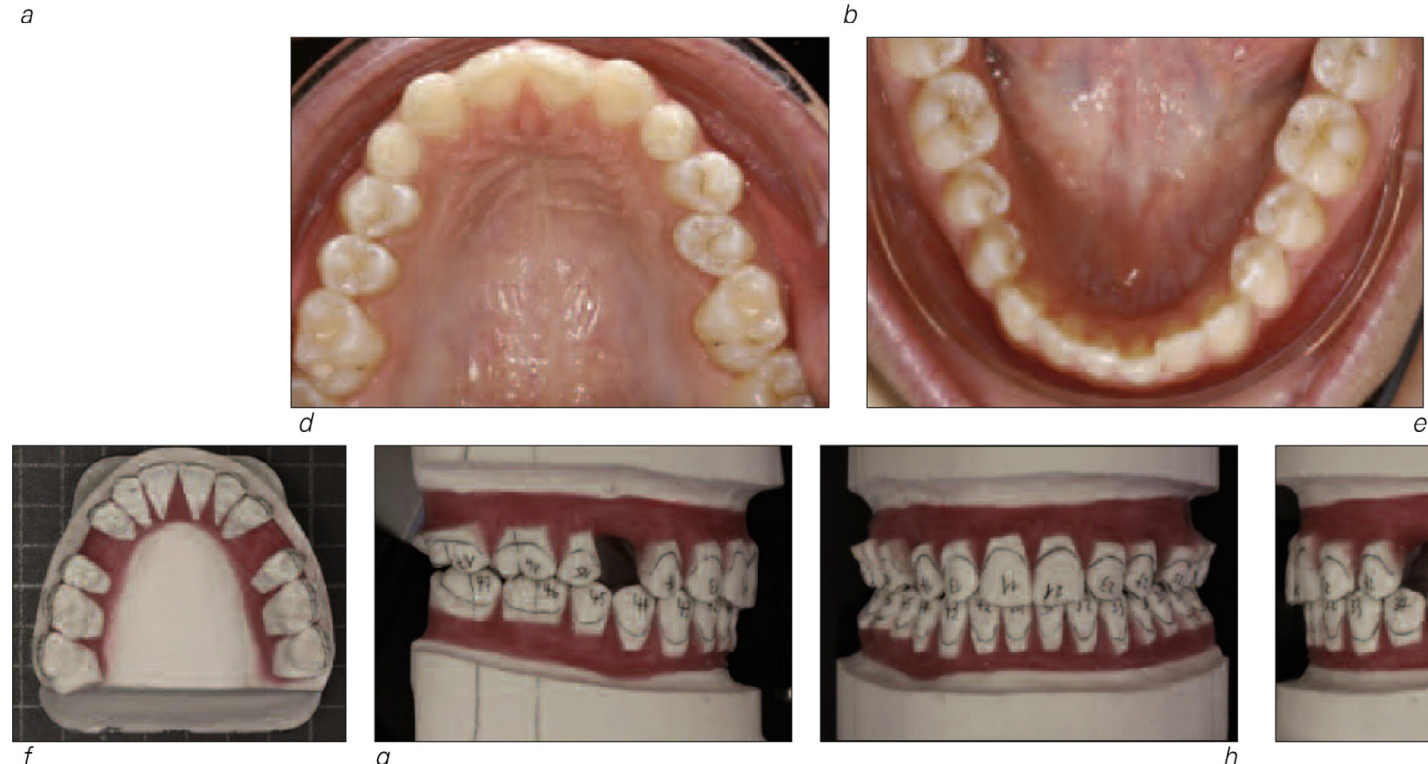

g
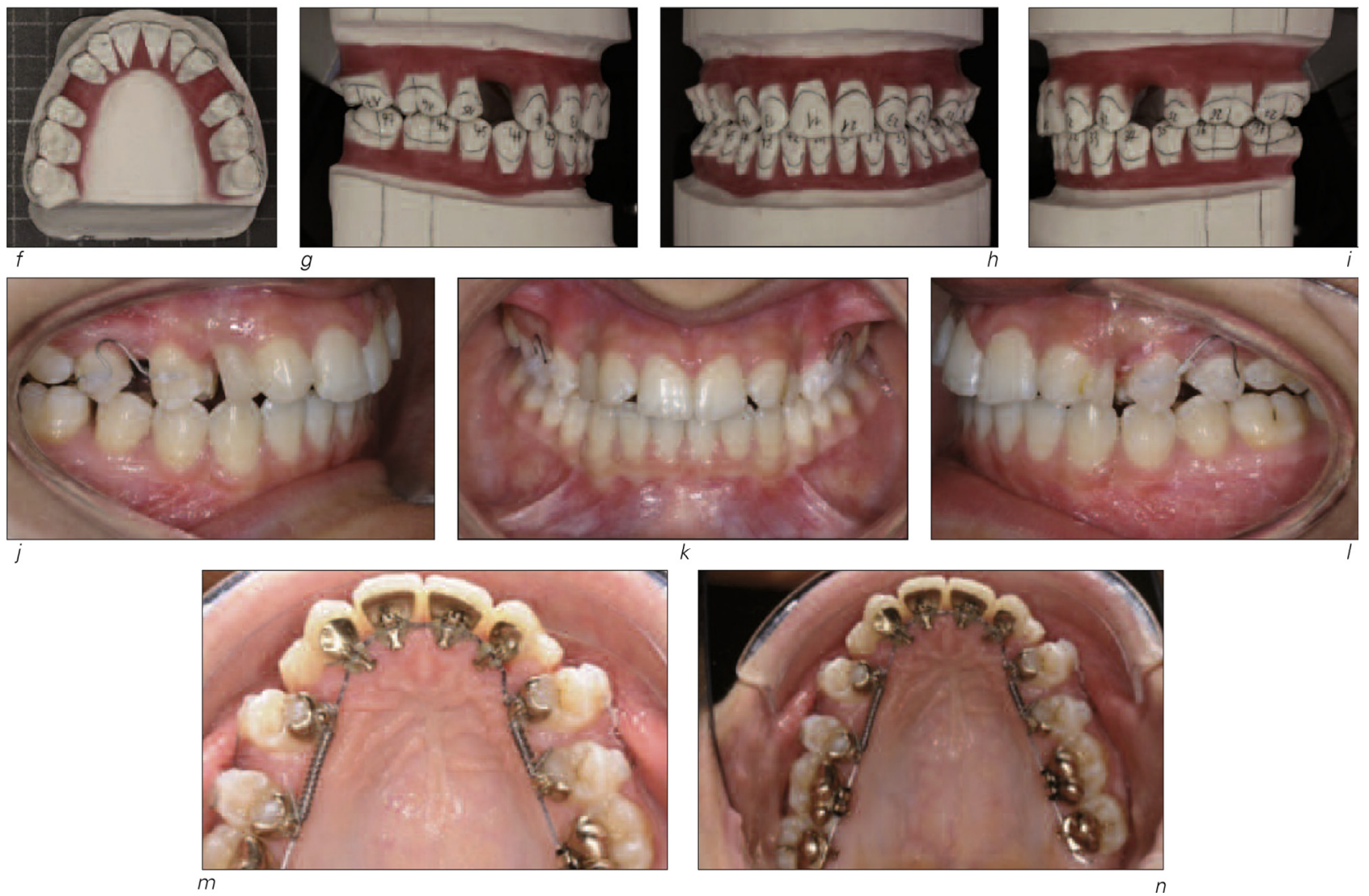

Figures $13 a$ to $13 n$

Course of treatment (Dr. Magali Mujajic) with reopening of spaces between first and second premolars. 


\section{3 - PARTICULAR MECHANICAL CONSIDERATIONS}

\section{3-1-Management of the anterior length of the arch}

Since crucial information is determined based on the ideal situation at the end of treatment, the insertion of the individualized brackets will be problematic as long as spaces from the missing teeth are present. This problem, which is resolved in cases of extractions of premolars because the possibility of ordering archwires with straight lateral sectors for the first phases of treatment, cannot be solved by the lab in this case.

Galletti $^{6}$ suggests four ingenious clinical solutions for managing the problem of a short wire:

- a canine is left free and the archwire is contralaterally displaced;

- the canines are ligated and the incisors are left untied;

- the archwire is sectioned in three parts by adding a continuous elastic chain for distal traction;

- a commercial archwire is bent to create a longer anterior portion.

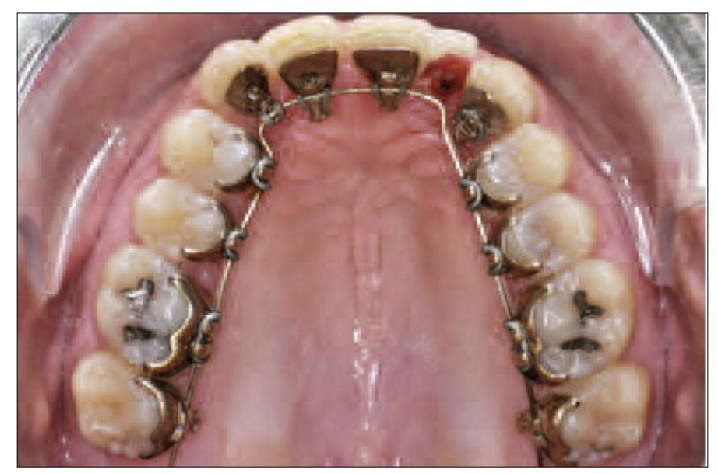

Figure 14

Clinical case $n^{\circ}$ 2. The super elastic archwire is moved to the right because of the high priority of leveling the upper right cuspid
This problem came up in the management of case $n^{\circ} 2$ when the upper left lateral was extracted.

Initially, we displaced the archwire towards the right without involving the upper left cuspid. We used a super elastic 16 by 22 archwire (Fig. 14).

This archwire turned out to be too short for use in the first solution. So we then made a 0.16 nitinol archwire to level the upper left cuspid and to deal with the strategic requirements discussed above (Fig. 15).

This momentary difficulty must be resolved as fast as possible in order to allow the practitioner to restore the archwire to the individualized brackets (Fig. 16). Notice the small distal margin on the canines left by the lab which complicates the insertion of the archwire.

\section{3 - 2 - Second order bend management}

As we have seen, the management of the angle of the canines has

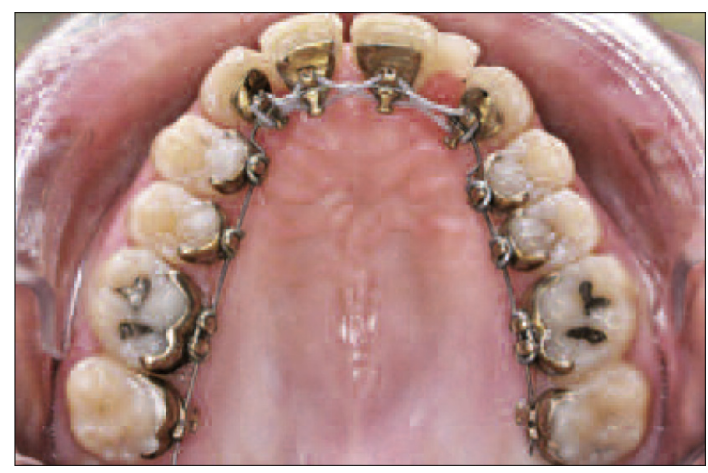

Figure 15

Clinical case $n^{\circ}$ 2. An 0.16 commercial nitinol archwire with canine offsets. 


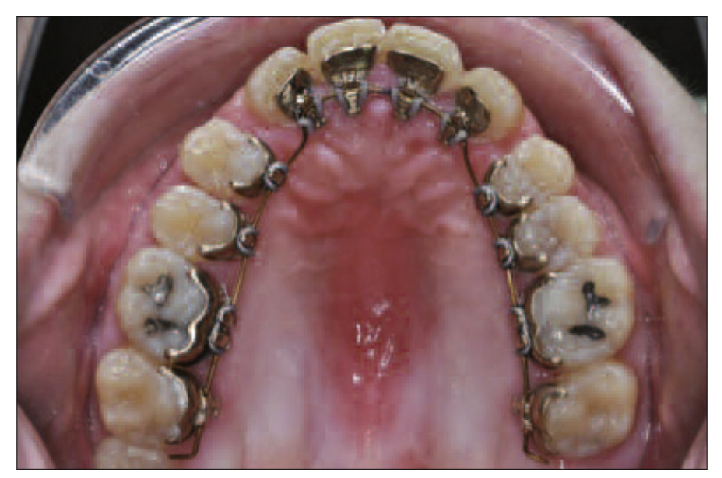

Figure 16

Clinical case $n^{\circ}$ 2. Insertion of the super elastic 16 by 22 archwire.

been delicate for clinical case no 2 which has made us doubt how right the protocol is which has as its goal to regroup the four anterior teeth as a first-line treatment.

However, the analysis of initial documents shows a natural and particularly important angle of these teeth. The lab technician complied with this particular request during the preparation of the set-up (Fig. 17).

As with any second order problem, the practitioner has to resort to the usual way of correcting it by vertical insertion of the archwire into the anterior part of the arch:

- power-tie on the treated tooth and on the neighboring teeth;

- TMA 175-175 finishing archwire with sub-angulation of $-10^{\circ}$ on the canines.

\section{3 - 3 - Management of anchorage}

If the mechanics of closing spaces does not change in relation to classic mechanics, i.e. regression "on mass" of the anterior sector on the steel $16^{*} 24$ archwire with torque supplement and straight lateral sectors, it is imperative to take into account an anchoring values of each tooth in order to evaluate the amount of necessary anchorage for achieving a smooth working of the closing movement.

Recent works by El-Nabbout ${ }^{4}$ using 3D imaging have outdated the work of Jarabak and Freeman ${ }^{5}$. El-Nabbout is proposing a new chart of anchoring values for each tooth (Fig. 18).

Therefore, the anterior group of the central incisors and the canines represents a value of 8.5 whereas the resistance of the premolar-molar group is 23. The risk of loss of anchorage is therefore minimal.

Resorting to modern reinforced anchorage as Roussarie ${ }^{14}$ suggests with mini-screws or mini-implants can still be indicated.

In fact, the absence of the lateral incisor diminishes the resistance of the labial zone but the anterior position of the canine complicates its retraction given the proximity of its apex to cortical bone.

Torque supplement in the anterior region of the retraction arch seems to us to be essential, both to limit regressive movement and to withdraw the canine apex from cortical bone.

Anchorage can be reinforced by a symmetrical or asymmetrical intermaxillary elastic mechanism depending on the clinical context (Fig. 19). 

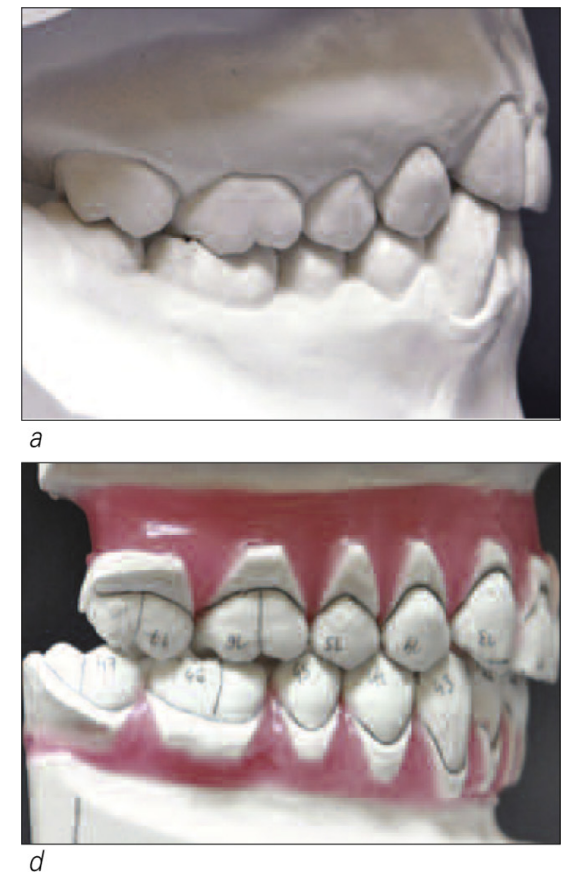

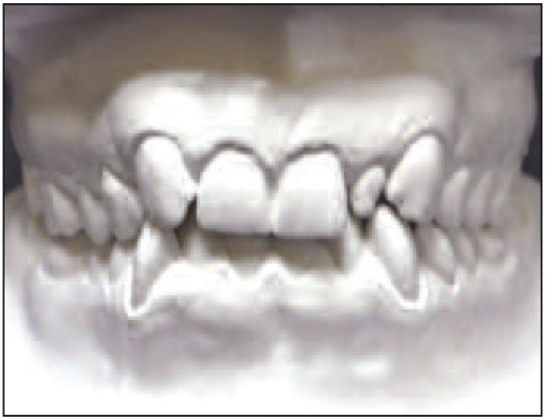

$b$
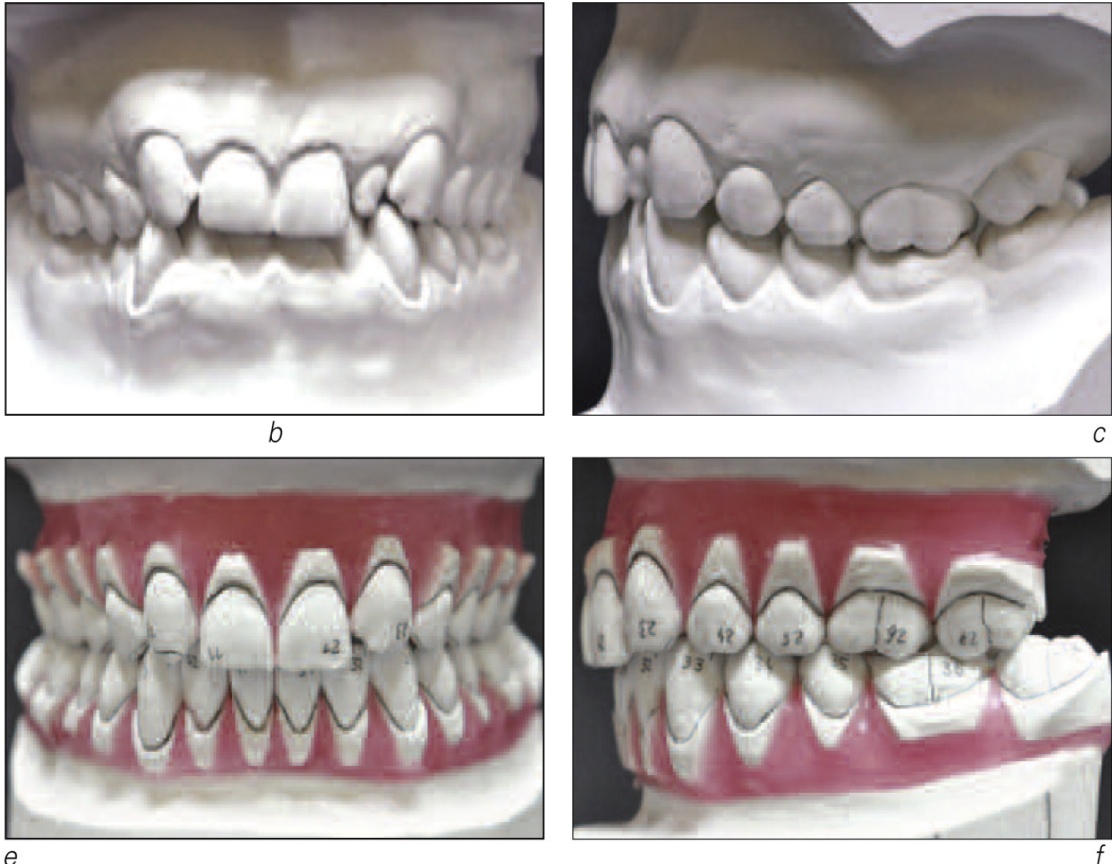

Figures 17a to $17 f$

Clinical case $n^{\circ}$ 2. Castings from beginning to set-up.

\section{3-4-Management of parasitic movements}

We have already discussed the problem linked to regrouping the front four teeth on the level of the second order.

During the closing phase of space closing, there is good reason to be aware of the "bowing effect" on the shape of the upper arch. It would be a prudent then to install a "double cable" mechanism either uni- or bilateral, with which the practitioner can vary the intensity of the buccal and lingual force based on the desired effect (Fig. 20).

Another parasitic effect in the course of retraction consists of a lingual-version of the anterior block.
This block can be controlled by a torque supplement.

\section{3 - 5 - Management of the end of treatment}

Typically, the final stage of treatment is achieved with beta-titanium archwires.

The practitioner can adjust:

- the inter-canine distance;

- the angulation;

- the torque;

- the in-out;

- the dental height.

Remember that:

- the 175 by 175 is a sub-dimensional archwire which ensures an excellent finish of the $1^{\text {st }}$ and $2^{\text {nd }}$ anterior order; 


\begin{tabular}{|c|c|c|c|c|c|c|c|c|c|c|c|c|c|c|}
\hline & U1 & U2 & U3 & U4 & U5 & U6 & U7 & L1 & L2 & L3 & L4 & L5 & L6 & L7 \\
\hline $\begin{array}{c}\text { Root } \\
\text { surface } \\
\text { in } \mathrm{mm}^{2} \\
\text { (Freeman) }\end{array}$ & 230 & 194 & 282 & 312 & 254 & 533 & & 170 & 200 & 270 & 237 & 240 & 475 & \\
\hline $\begin{array}{c}\text { Root } \\
\text { volume } \\
\text { in } \mathrm{mm}^{3} \\
\text { (this study) }\end{array}$ & 321 & 209 & 366 & 287 & 296 & 594 & 545 & 162 & 171 & 306 & 240 & 282 & 564 & 534 \\
\hline $\begin{array}{c}\text { Jarabak } \\
\text { value }\end{array}$ & 4 & 3 & 8 & 7 & 6 & 9 & & 1 & 2 & 8 & 5 & 5 & 10 & \\
\hline $\begin{array}{c}\text { Anchorage } \\
\text { value } \\
\text { (this study) }\end{array}$ & 2 & 1,5 & 2.25 & 2 & 2 & 4 & 3,5 & 1 & 1 & 2 & 1,5 & 2 & 3,5 & 3,5 \\
\hline
\end{tabular}

Figure 18

Comparison of the anchorage values proposed by El-Nabbout with Freeman and Jarabak values.

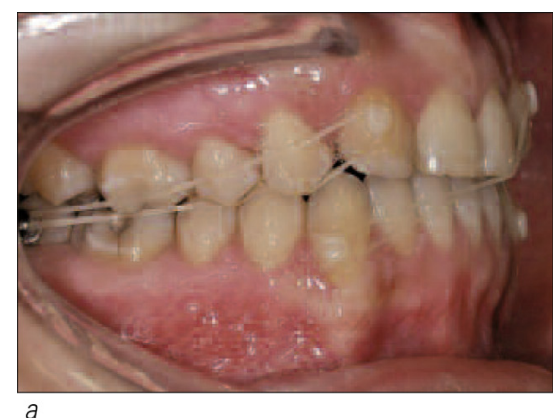

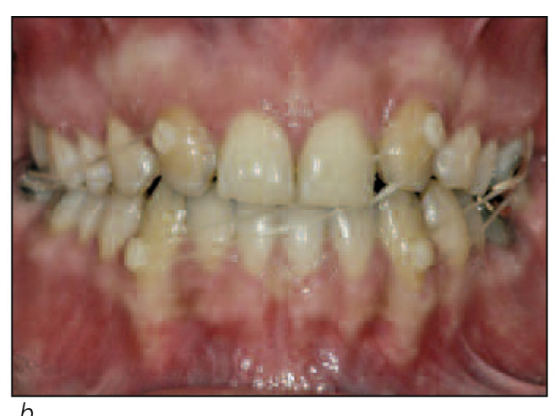

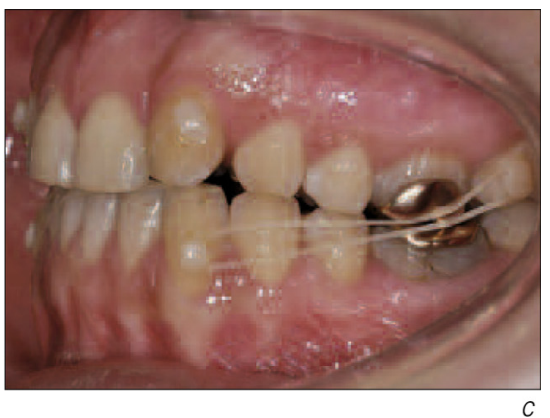

Figures 19a to $19 \mathrm{c}$

Clinical case $n^{\circ}$ 2. Asymmetrical elastic mechanism promoting anchoring to the right and a loss of anchoring to the left.

- the 1725 ensures an excellent finish of the $2^{\text {nd }}$ posterior order since it occupies the entirety of the throat in the height dimension;

- the 182 by 182 ensures an excellent finish of the $3^{\text {rd }}$ anterior order. It is the most used archwire which is also indicated in cases of ageneses of the lateral incisors (Fig. 21).

Notice that there is a possibility of asking for an overcorrection of the torque for the canines in order to make it possible to eliminate the canine bump on the periodontium; 

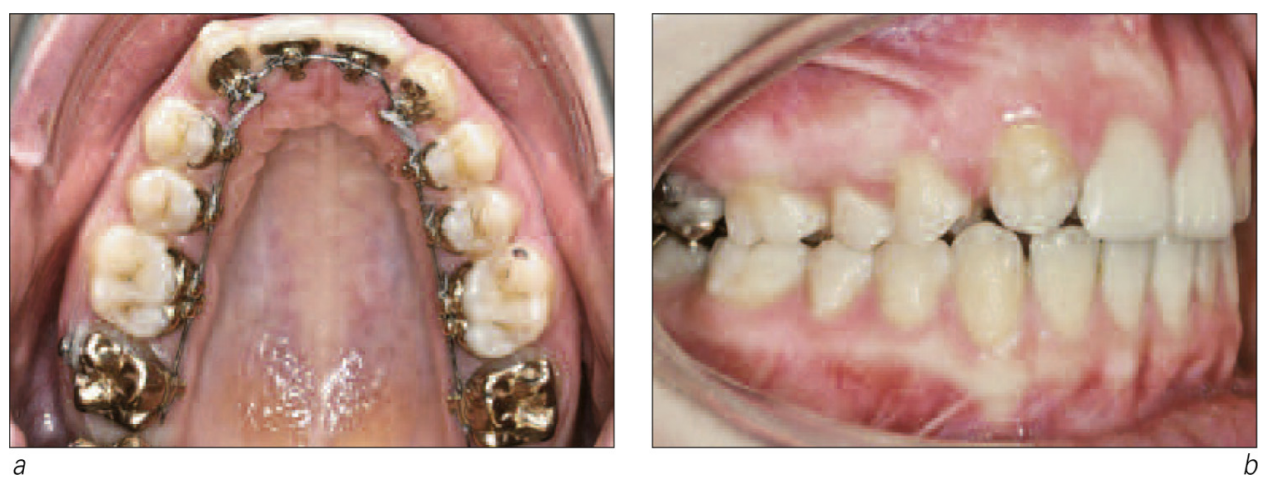

Figures 20a and 20b

Clinical case $n^{\circ}$ 1. A "double-cable" mechanism is installed on the right side in order to facilitate retraction and to limit the parasitic effects. Note the dot of resin in the buccal zone from the canine which can no longer be gingival for periodontal reasons despite its unattractive appearance because of its excessively anterior position.

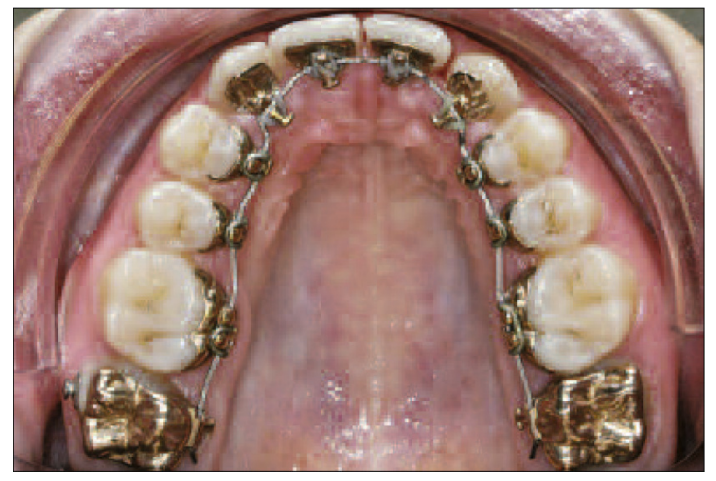

Figure 21

Clinical case no 1. Finishing touches using $182 * 182$ beta-titanium and correction of the tip of 21 using power ties and stripping.

- the $182 * 25$ makes it possible to both have a posterior $2^{\text {nd }}$ order finish, and a $3^{\text {rd }}$ order anterior finish in the transversal direction.

The ancillary means at our disposal are:

- the set-up in order to check what was planned for by the lab and to evaluate if there is any reason to make overcorrections or even to order new archwires with specific data;

- articulated paper to visualize the possibility of making selective castings of the bases;

- using Masel type pliers to crimp archwires without removing them.

- inter-maxillary elastics in order to obtain a perfect inter-arch coordination in the three dimensions of space; 3.5 ounce bands $3 / 16^{\text {th }}$ in the saggital dimension and 3.5 ounces $1 / 8^{\text {th }}$ in the vertical and transverse dimension;

- the power-ties in order to manage problems of angle and torque;

- stripping using Sheridan drill bits or diamond bands.

The occlusal finishing touches, besides their essential role in stabilizing the long-term results, must facilitate masquerading of the canines into 

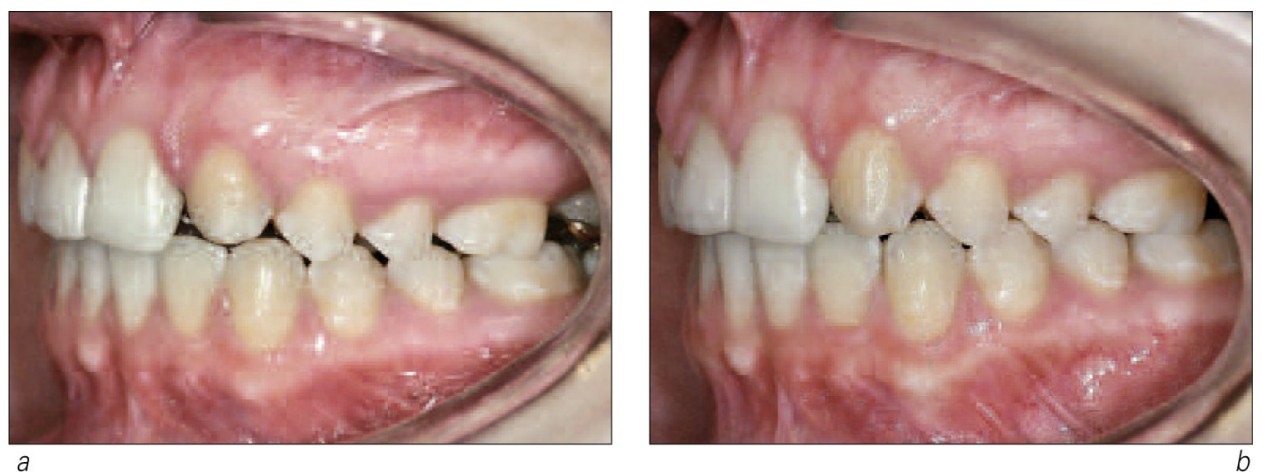

Figures 22a and 22b

Clinical case no 1 before and after end of treatment: a first order adjustment made it possible to vertically coordinate the lateral sectors. The occlusal finishing touches of the canines will take 5 months to complete.

lateral incisors. Therefore, it is recommended that the practitioner seek

\section{$4-$ CONCLUSION}

- A lingual technique with customized braces performs well in the treatment of cases of agenesis of upper lateral incisors by closing spaces in the following way:

- the goals of treatment are predictable and even modifiable by using an initial set-up and this modification is performed before fabrication of the device.

The protocols for treatment of agenesis are not unanimously agreed upon and this leads each practitioner to make an "acceptable compromise" in each case.

The set-up then becomes an incomparable tool for making a good choice of treatment. Additionally, it is an excellent pedagogical tool for justifying our choice of treatment to our patient: the advice of a prosthodontist before planning retention (Fig. 22).

- that the creation of an individualized device will lend an immeasurable finesse to the occlusal adjustment and to the tridimensional positioning of each dental element, especially in relation to the maxillary canines whose angle and torque must be especially well adapted;

- that the commercial buccal devices which come with no torque or angle data pertinent to our occlusal choice; the practitioner must be able to skillfully and carefully improvise to obtain the same end of treatment occlusion;

- that the patient, who oftens develops an inferiority complex at the beginning of adolescence due to unattractive congenitally missing teeth, will be particularly drawn to an invisible orthodontic technique. 
The author would like to take this opportunity to say thank you to the teaching staff of the Dental University of lingual orthodontics of Garancière for their immeasurable and highly professional assistance during the procedures that are presented in this article.

\section{REFERENCES}

1. Canal $P$, Chabre $C$. Agénésie des incisives latérales supérieures: quel traitement ? Question mise en discussion. Orthod Fr 1987;58(2):791-4.

2. Canal P, Salvadori A. Orthodontie de l'adulte. Paris : Elsevier Masson SAS, 2008.

3. Dueled E, Gotfredsen K, Trab Damsgaard M, Hede B. Professional and patient-based evaluation of oral réhabilitation in patients with tooth agenesis. Clin Oral Implants Res 2009;20(7):729-36.

4. El-Nabbout F. L'apport du scanner 3D en anatomie dentaire : résultats et applications aux calculs d'ancrage et à la mécanique orthodontique. Thèse Doct. Univ. Toulouse : Université Toulouse III, Paul Sabatier, 2007.

5. Freeman D.C. Root surface area related to anchorage in the Begg technique. Master's thesis. Memphis: University of Tenessee, 1965.

6. Galletti C, Mujagic M, Simon JS. Orthodontie linguale : positionnement du premier arc dans la zone antérieure. Intern Orthod 2007;5:301-26.

7. Jarabak JR, Fizzell JA. Technique and treatment with the light-wire appliances. $2^{\text {nd }}$ ed. StLouis : Mosby Co ed, 1972.

8. Jemt T. Measurements of tooth movements in relation to single implant restorations during 16 years: a case report. Clin Impl Dent Relat Res 2005;7(4):200-8.

9. Jemt T. Single implants in the anterior maxilla after 15 years of follow-up: comparison with central implants in the edentulous maxilla. Int J Prosthodont 2008;21(5):400-8.

10. Jung RE, Pjetursson BE, Glauser R, Zembic A, Zwahlen M, Lang NP. A systematic review of the 5year survival and complication rates of implant-supported single crowns. Clin Oral Implants Res 2008;19(2):119-30.

11. Rosa $M$, Zachrisson BU. Integrating esthetic dentistry and space closure in patients with missing maxillary lateral incisors. J Clin Orthod 2001;35(4):221-34.

12. Rosa M, Zachrisson BU. Integrating space closure and esthetic dentistry in patients with missing maxillary lateral incisors: further improvements. J Clin Orthod 2007;41 (9):563-73.

13. Rosa M, Zachrisson BU. The space-closure alternative for missing maxillary lateral incisors: an update. J Clin Orthod 2010;44(9):540-9.

14. Roussarie F, Lesage C, Moatty F. Traitement d'une malocclusion sévère de l'adulte. Orthodontie minivis et fibres. Inf Dent 2008;29(3):1567-73.

15. Thilander B, Odman J, Lekholm U. Orthodontic aspects of the use of oral implants in adolescents: a 10-year follow-up study. Eur J Orthod 2001;23(6):715-31. 